\title{
Responsibility of scientists
}

Francesco Calogero

I feel it is much preferable, rather than writing about Victor Weisskopf myself, to report the words of others who were closer to him than I - although I did have the privilege to meet him several times - and especially to quote his own words, in particular those that demonstrate his struggle with crucial decisions as well as his reflections that ring like those of a prophet.

So, I begin by reporting some of the commemorative words pronounced at the last Annual Pugwash Conference, held in August 2002 at the San Diego campus of the University of California, by Sir Joseph Rotblat. Indeed Weisskopf and Rotblat - Viki and Jo to their friends - have much in common: both were born in 1908, both were a part of - as Jo said in La Jolla referring to Viki - "Hitler's gift...[to] the US and Britain" [1], both ended up in Los Alamos - where they became good friends - to help create the first nuclear weapons, both were motivated to do so "by the fear that Hitler could have an atomic bomb before the West did" [2], and both felt after 1945 the responsibility to do whatever they could to avoid the danger that nuclear weapons be again used to kill.

\section{An ardent campaigner}

Rotblat said of Weisskopf: "Immediately after the Hiroshima and Nagasaki bombs he became one of the most ardent campaigners to prevent further use of nuclear weapons. This made him a 'natural' for Pugwash. Indeed he was one of the 'originals' - the name we give to the small group of participants in the first Pugwash Conference, in 1957. With his death, only five of the originals are left." (In the official picture of the group taken in Pugwash, a few of the 22 participants are missing, and Viki is one of them - maybe he was talking physics with Yukawa, who also is missing from that photo.)

Rotblat in La Jolla went on to say: "In one of his speeches at a Pugwash Conference Viki said: 'We all dream of a world without nuclear weapons...But we should dream of a world order where people may be justified in saying: Nuclear Weapons? Who cares?' Unfortunately, the world order now is one in which people say this, while some 30000 nuclear weapons are still in the arsenals, many of them on hair-trigger alert. We have still a long way to go to fulfil Viki's first dream, a world without nuclear weapons."

On 26 September 1989, Viki delivered the third Olof Palme Memorial Lecture in Stockholm (this series of annual public lectures was initiated by the Stockholm International Peace Research Institute (SIPRI) in 1986; the first two lectures were delivered by Willy Brandt, former chancellor of Germany and by Marshal Sergey Akhromeyev, then chief of the general staff and first deputy minister of defence of the Soviet Union). The title he chose was "The responsibility of scientists in the nuclear age". The rest of this text consists of quotations from that speech [2].

"The responsibility of scientists is a wide subject, with many ramifications, and my talk will cover only some of its aspects. I would like to start with a personal event in my life. In 1929 I was a student

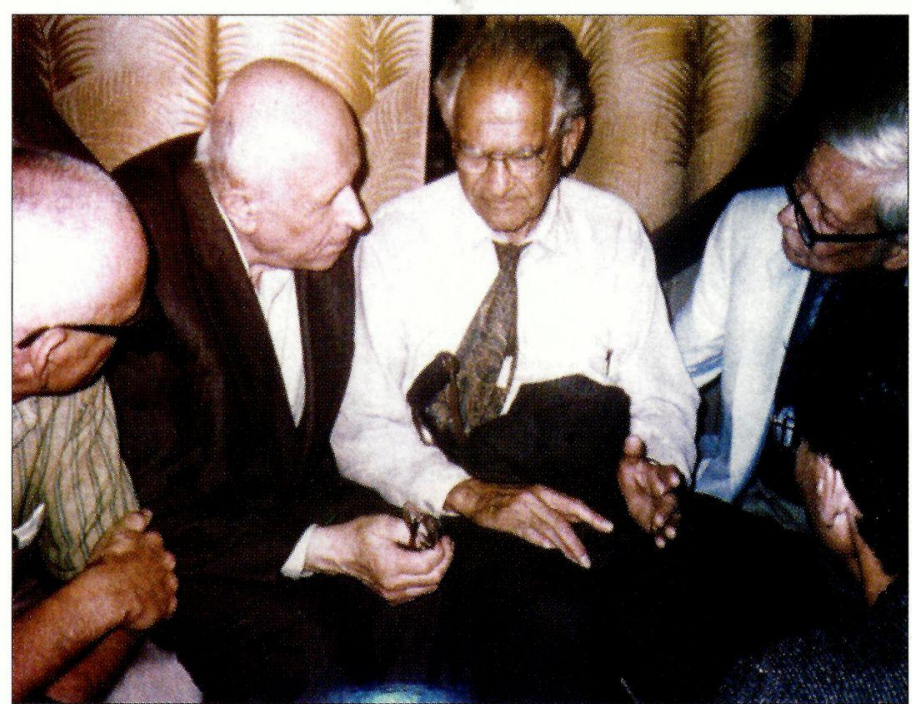

August 1988, at Moscow airport, waiting for the flight to attend the 38th Annual Pugwash Conference in Dagomys, the Soviet Union. From left to right: Francesco Calogero, Andrei Dimitrich Sakharov, victor Weisskopf and Rudolph Peierls.

of Max Born studying quantum mechanics in Goettingen. This was and is a rather difficult and esoteric subject, and at that time I wanted to change to medicine. I felt that medicine had more relation to human beings compared with the abstract and esoteric study of theoretical physics. Max Born said to me: 'No, you should stay in physics. You will see how deeply the new physics will be involved in human affairs.' How right he was in many respects, both positive and negative. We should not forget the positive effects: new technology and the deeper understanding of atomic structure have helped humankind in many ways. The negative effects, of course, have been rather terrible: the new weapons of war, the nuclear bomb and other terrible things of this kind. [...]

\section{Joining the programme}

"In 1942, as a recent immigrant to the US, I decided to join the [nuclear weapon] programme because of the overriding fear of Hitler and to help a host country that had received me with so much grace. We did not know that Hitler had not developed the bomb. It is an important question, and one that I cannot answer, whether the CIA or the British Secret Service knew this. They did not tell us. I do not want to accuse them, but it may be that they did not want to tell us because they wanted the bomb to be constructed. However, I have no proof of this.

"A very interesting moment as regards the feeling of responsibility actually came in May 1945 at the time of Hitler's defeat, when it was clear that he did not have the bomb. Now, should we continue? Should we go on working on this weapon of mass destruction? We all, or almost all, continued [Joseph Rotblat quit at the end of $\triangleright$ 
1944]; we were three months from the completion of the weapon and unfortunately, I say this with a certain feeling of shame, werdid not think, at least I did not think, of stopping at that moment. The rationalizations were that the war with Japan was killing many, many people - there were 40000 victims of the fire bombing each day and an invasion would cost a million deaths on each side. These were rationalizations; in any event we went on. Perhaps unfortunately, one of the reasons was the attraction of the problem. Since we had worked almost day and night for three years, and were just three months from the fulfilment of this work, it was almost unthinkable not to continue. Robert Oppenheimer coined a term; which I do not like very much, namely, 'technically sweet'. There is a lesson here, a dangerous lesson. Today we have similar 'technically sweet' problems in America, for example, for those people who work on the Strategic Defense Initiative (SDI) programme. Some of these people know that SDI - Star Wars - would really do more damage than good if it was ever to succeed - a question in itself - but because the programme presents interesting, technically sweet, problems some scientists are attracted to work on them.

\section{Ethical questions}

"When we knew the war would soon be over, ethical questions arose. What was this weapon? What would it mean for mankind? At that time, Niels Bohr joined the group at Los Alamos. He always taught us that we are responsible for our work. At that time, of course, we did not have much influence on what the government would do with the bomb. There were four possibilities.

"The first possibility was not to use the bomb at all. The second was to demonstrate its use on an uninhabited area. The third was to demonstrate the bomb over a military target, for example, a harbour where a large concentration of the Navy was assembled. The fourth possibility was to throw it over an inhabited city. Nobody took the first option seriously. It was unthinkable that the military would desist from using its most potent weapon in a war. A number of physicists, in particular those under the influence of James Frank, wrote a memorandum to the government, supporting the second option, but the government was unimpressed, afraid that the bomb might fizzle out and amount to nothing. Unfortunately, the third option was not considered either, and the fourth was the solution chosen as the one that would make the biggest impression on the world. The destruction of Hiroshima was bad enough but, looked at today, the decision to destroy a second city after three days was certainly a crime. [...]

"The following six points somehow summarize in a very superficial way my view of the responsibility of scientists of all kinds, not only natural scientists, but also social scientists, engineers and statesmen - in other words, everybody:

- to prevent war;

- to prevent environmental catastrophe;

- to provide a creative, purposeful life for the majority;

- to provide assistance and education for the Third World;

- to insist on freedom of thought and the value of doubt;

- and to create an awareness of complementary attitudes.

"These points are not listed in order of importance; they are all equally important. First, we must help to prevent wars. We must show how terrible war is; this is already slowly penetrating into people's minds. It makes little difference whether we speak of nuclear or conventional war. Even conventional war is terrible, and if the pow- ers have nuclear weapons, then the losing side will certainly use them. The public must be made aware of how destructive modern weapons are. We must help arms reduction by proposing new methods of verification. Second, we must help to prevent environmental catastrophe. I am not sure myself whether this is not even the greater problem. To prevent a nuclear war is simple: do not use nuclear weapons. We do not even know exactly what causes environmental catastrophes and, as I said before, we face enormous political and social difficulties. Scientists must explain the processes leading to the catastrophes, expose technical abuses and redirect technical and societal creativity towards solutions.

"Third, we must provide a creative, purposeful life for the majority of the population, a very difficult but necessary task. Fourth, we must help to solve Third World problems by assistance and education. This is always a very difficult problem since it is very easy to feel superior because we are advanced. We are not superior, we are just further ahead - both in use and in abuse - but we still have to help them in many ways. Fifth, it is our responsibility as scientists to proclaim freedom of thought - to teach how doubt and discussions of different opinions are important. We have to demand the freedom for discussion and doubt to be recognized in all communities, and we know very well that the fight is far from won.

"Finally, and here I speak as a Bohr disciple, we must create a sense of complementary attitudes. What do I mean by this? There are several, indeed many, approaches to human problems apart from a scientific one: ethical, artistic and religious. They are not contradictory but complementary to science. Science can never decide what is good and what is bad, what is beautiful and what is ugly, or what is or is not great art. Education should not only be in science; it should attach equal importance to all these approaches so as to teach tolerance and even enthusiasm for the variety of human endeavours. Whenever one way of dealing with the human situation is dominant, abuses come about.

\section{A sense of complementarity}

"In medieval times, when the religious view was the dominant one, there were crusades, the Inquisition and the religious wars; today, in some ways, the scientific-technical 'religion' is dominant. The abuses are only too well known. What we need is a sense of complementarity. This is not relativism. It is not a denial of values to say that everything has values. Ethical principles and a value system must be derived from many sources, not just one, in order to foster openness and understanding for the different complementary approaches to the realities of life. I think that these are the preconditions for the survival of our civilization. It can provide us with much that is good, beautiful and uplifting, but not yet for the majority of mankind. Once I said that what made my life worth living in the terrible days of Nazism that I lived through were Mozart and quantum mechanics. What I really meant was art and science, the great everlasting creations of the human mind."

\section{Further reading}

[1] www.pugwash.org.

[2] SIPRI Yearbook 1990: World Armaments and Disarmament (Oxford University Press) pp623-631.

Francesco Calogero, University of Rome "La Sapienza". 